American Journal of Applied Sciences 4 (11): 908-911, 2007

ISSN 1546-9239

(C) 2007 Science Publications

\title{
Development of Criteria for Slab Compaction of Laboratory Roller Compactor (Turamesin)
}

\author{
Muniandy, R., Jakarni, F.M., Hassim, S. and Mahmud, A.R. \\ Department of Civil Engineering, Faculty of Engineering, Universiti Putra Malaysia \\ 43400 UPM Serdang, Selangor, Malaysia
}

\begin{abstract}
Laboratory experiments should simulate to a high degree the conditions in the field, especially in term of compaction procedures. Presently available laboratory compaction methods do not seem to be able to produce specimens that can truly represent the mixtures as it exists in the field, especially for Stone Mastic Asphalt (SMA) mixtures. SMA is highly dependent on the method of compaction. As the application of the SMA is rapidly gaining acceptance worldwide, a suitable laboratory compaction method is evidently needed. Turamesin, a laboratory slab roller compactor was developed to enable laboratory compaction of asphalt mixtures in field simulation conditions. This study was carried out in order to establish criteria for slab compaction and identify the potential of the newly developed Turamesin. A total of nine slabs were prepared with different combination of compactive efforts and data were then analyzed to develop correlation and thus to determine the appropriate values of the compactive efforts that resulted in optimum performance of the asphalt mix slab due to $4 \%$ air voids. For the asphalt mix slab to be compacted to the desired ultimate compaction of $4 \%$ air voids, the compactive efforts of $8.0 \mathrm{kgf} / \mathrm{cm}^{2}$ of applied pressure and 75 numbers of passes of the roller compactor were required. These values of compactive efforts were considered as typical parameters for Turamesin in achieving a target air void of $4 \%$ regardless of SMA mixtures.
\end{abstract}

Key words: Compaction, Field simulation, Slab, Air voids, Roller compactor

\section{INTRODUCTION}

Asphalt mix design is a laboratory simulation that is meant to simulate field manufacturing, construction and performance of pavement to the extent possible. Then, from this simulation, the best asphalt mixtures for pavement application and how it will perform as it is placed in the field can be predicted with certain reliability. Therefore, a realistic approach in developing and evaluating the asphalt mixtures is evidently needed, especially in terms of compaction procedure. Compaction is the process by which the volume of air in asphalt mixtures is reduced by using external forces to reorient the constituent aggregates particles into a more closely spaced arrangement, thus produces a corresponding increase in density ${ }^{[8]}$. Compaction plays a major role in the performance of asphalt mixtures. Mixture properties such as air voids and density are highly dependent on the degree and method of compaction, and these properties in turn affect pavement performance indicator such as rutting and fatigue cracking ${ }^{[5]}$.

Past studies have shown that if the field conditions for which mixtures are being designed are different from those for which the design method was developed, the mixtures may not be adequate for service even though it is designed according to the method ${ }^{[3,5]}$. Therefore, it is important that laboratory compaction procedure of asphalt mixtures should be able to achieve materials and engineering properties such as density, air voids and resilient modulus as closely as possible to those of the materials placed in the field using standard compaction practices. Over the years, several laboratory compaction methods have been developed to simulate field compaction. These include impact, kneading, vibratory and rolling compaction. Also, a lot of studies have been done on comparative evaluation of the various laboratory compaction methods based on their ability to simulate field compaction. Conclusions of different studies have indicated that rolling wheel compaction simulate properties that are closer to field compaction $^{[4,6,9]}$.

Background: Rolling wheel compactor is considered to be one of the methods that closely simulate field compaction and appeared to duplicate field compacted specimens quite well ${ }^{[9]}$. Unlike gyratory and kneading method, rolling wheel compactor does not include any static leveling loading that might increase particle to particle contact by crushing aggregates together ${ }^{[5]}$. However, the rolling wheel compactor is not widely

Corresponding Author: Jakarni, F.M., Department of Civil Engineering, Faculty of Engineering, Universiti Putra Malaysia, 43400 UPM Serdang, Selangor, Malaysia, Tel: ${ }^{2}+60389464421$, Fax: +60386567129 
used as standard laboratory compaction equipment due to difficulties in controlling air voids with the finished specimens than other compaction method ${ }^{[2]}$. In addition, the procedures for preparing the laboratory specimens is quite tedious and large quantities of aggregates-asphalt mixtures need to be prepared in order to produce an asphalt mix slab. The currently available rolling wheel compaction devices are found to be expensive, bulky in size and not easily portable. This has caused the researchers to look into a more simplified version of compactor such as gyratory compactor, although rolling wheel compactor is intuitively appealing for its obvious similarity to field compaction process ${ }^{\text {[6] }}$.

Therefore, researcher at Universiti Putra Malaysia have come out with a new roller compactor called Turamesin to provide a solution to the problem of producing laboratory specimens which are representative of materials laid and compacted in the field. Turamesin is used to compact asphalt mixtures using a steel wheel roller just like the heavy duty steel wheel roller on-site. The compactor also provides a variable slope from $0^{\circ}$ to $20^{\circ}$ from horizontal plane for the purpose of skid resistance analysis and hydroplaning studies. Different levels of pressure can be applied up to approximately $10.0 \mathrm{kgf} / \mathrm{cm}^{2}$ (143 psi) through a pneumatic system.

The objective of this study was to establish criteria for Turamesin in compacting asphalt mix slab and analyze its performance as an improved laboratory compaction device. In order to establish criteria for slab compaction, two variables of Turamesin were identified as being significantly important in affecting the properties and performance of the compacted slab ${ }^{[7]}$. These variables are applied pressure and number of passes of the roller.

\section{MATERIALS AND METHODS}

In this study, $14 \mathrm{~mm}$ Stone Mastic Asphalt (SMA) mixtures with granite aggregates and modified rubberized asphalt were used and determination of the optimum asphalt content was done through Marshall mix design analysis in accordance with ASTM D155982. The properties of the aggregates and asphalt used in this study were tested in accordance with ASTM, AASHTO and BS standards. All the test results were conformed to the specification requirements. The optimum asphalt content value from the Marshall mix design analysis and the Theoretical Maximum Density (TMD) based on Rice Method (ASTM D2041) for the respective value were found to be $5.77 \%$ and 2.4200 $\mathrm{g} / \mathrm{cm}^{3}$ respectively. Once the optimum asphalt content value was obtained, the amount of materials required for each slab was calculated using the volume-density calculations with target air voids of $4 \%$. The target air voids was selected as $4 \%$ based on research and past performance that shown that the value is ideal for asphalt mixtures.

Two variables of Turamesin were identified as being significantly important in affecting the properties and performance of the compacted slab. These variables are applied pressure and number of passes of the roller. A study on the effect due to variation of applied pressure and/or number of passes of the roller compactor on bulk density and air voids was then conducted. A total of nine slabs were prepared in accordance with Method of Specimen Preparation of Asphalt Mix Slab Using Turamesin with different combinations of applied pressure and number of passes of the roller compactor. Table 1 provides the experimental matrix for the various combinations of the compactive efforts. Each compacted slab was then cut into nine blocks of equal size $(166 \mathrm{~mm} \times 150 \mathrm{~mm} \times 70$ $\mathrm{mm}$ ), and analysis of bulk density and air voids were performed. Results of the analysis were then analyzed to develop a correlation between the compactive efforts and properties of the compacted slab. The overall test procedures involved are shown in Fig. 1.

Table 1: Experimental Matrix for Combination of Compactive Efforts

\begin{tabular}{cccc}
\hline $\begin{array}{c}\text { Number of } \\
\text { Passes }\end{array}$ & \multicolumn{3}{c}{ Applied Pressure $\left(\mathrm{kgf} / \mathrm{cm}^{2}\right)$} \\
4.0 & 6.0 & 8.0 \\
\hline 20 & Slab 1 & Slab 4 & Slab 7 \\
40 & Slab 2 & Slab 5 & Slab 8 \\
60 & Slab 3 & Slab 6 & Slab 9 \\
\hline
\end{tabular}

\section{RESULTS AND DISCUSSION}

Values of bulk density and air voids due to specified pressure and number of passes of the roller are given in Table 2. Figure 2 summarizes the results. As seen in the table and figure, bulk density and hence air voids increase as the applied pressure and/or number of passes of the roller compactor increase respectively. This increase was expected since increasing compactive effort in term of pressure and number of passes will force the mixtures particles closer together.

All the tabulated data show a positive quadratic curvilinear relationship at which bulk density increases at a changing rate of number of passes of the roller compactor for each specified pressure, but this increase tapers off beyond approximately 80 numbers of passes. Beyond this point, bulk density start to experience a slow rate of increasing and expected to reach a steadystate condition, which can be defined as ultimate density. Continued rolling beyond this point is wasteful and can even be detrimental to pavement finish, in some cases. 


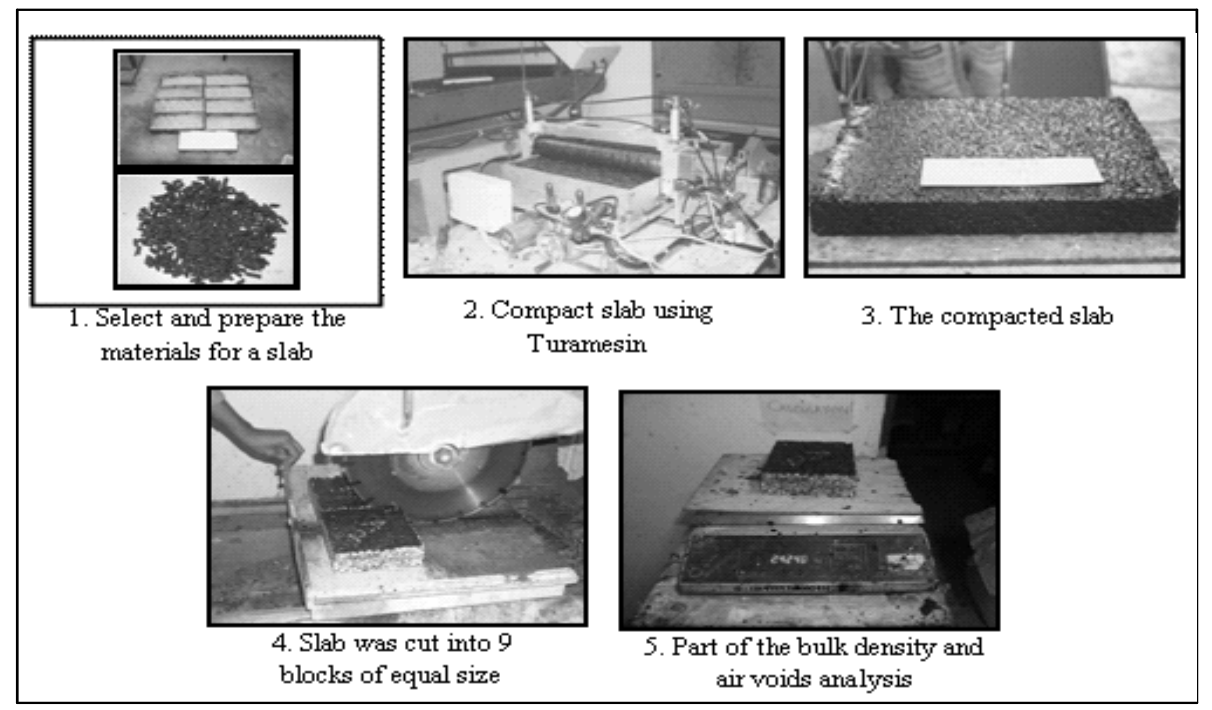

Fig. 1: Test Procedures Involved

Table 2: Results for Bulk Density and Air Voids Analysis

\begin{tabular}{ccccc}
$\begin{array}{c}\text { Applied Pressure } \\
\left(\mathrm{kgf} / \mathrm{cm}^{2}\right)\end{array}$ & Number of Passes & $\begin{array}{c}\text { Average Bulk } \\
\text { Density }\left(\mathrm{g} / \mathrm{cm}^{3}\right)\end{array}$ & TMD $\left(\mathrm{g} / \mathrm{cm}^{3}\right)$ & Air Voids (\%) \\
\hline 4.0 & 20 & 2.2601 & 2.4200 & 6.61 \\
4.0 & 40 & 2.2900 & 2.4200 & 5.37 \\
4.0 & 60 & 2.299 & 2.4200 & 4.96 \\
6.0 & 20 & 2.2802 & 2.4200 & 5.79 \\
6.0 & 40 & 2.2999 & 2.4200 & 4.96 \\
6.0 & 60 & 2.3100 & 2.4200 & 4.55 \\
8.0 & 20 & 2.2999 & 2.4200 & 4.96 \\
8.0 & 40 & 2.3101 & 2.4200 & 4.55 \\
8.0 & 60 & 2.3200 & 2.4200 & 4.13 \\
\hline
\end{tabular}

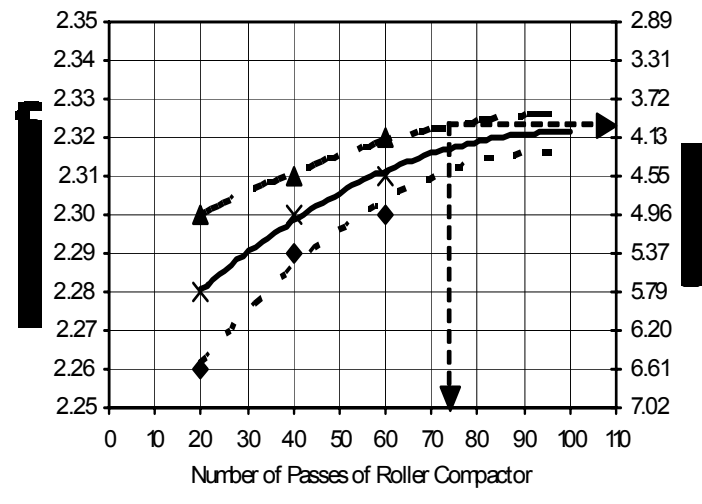

- - $.4 .0 \mathrm{kgf} / \mathrm{cm}^{2} \longrightarrow 6.0 \mathrm{kgf} / \mathrm{cm}^{2}--8.0 \mathrm{kgf} / \mathrm{cm}^{2}$

Fig. 2: Correlation between Compactive Efforts and Physical Properties of the Compacted Slabs
Bulk density and air voids are directly related to each other, thus a closely controlled density is required to ensure air voids stay within an acceptable range ${ }^{[1]}$. Research and past performance have shown that a final compacted void content of $4 \%$ is ideal for asphalt mixtures. Therefore, air voids obtained during mix design or from laboratory compacted specimen should be an estimate of the final compacted void content of $4 \%$. For this reason, $4 \%$ were selected as the target air voids in order to establish criteria for slab compaction using Turamesin. Based on Fig. 2, the desired air voids was achieved when $8.0 \mathrm{kgf} / \mathrm{cm}^{2}$ of pressure was applied with number of passes of the roller compactor between 70 and 80 . When the applied pressure was reduced to $6.0 \mathrm{kgf} / \mathrm{cm}^{2}$, the same value of air voids may be achieved with higher number of passes of the roller compactor. Increasing the applied pressure above 8.0 $\mathrm{kgf} / \mathrm{cm}^{2}$ seems to be impossible due to maximum limit 
of the pressure gauge of $10 \mathrm{kgf} / \mathrm{cm}^{2}$. Therefore, the optimum value for applied pressure and number of passes to result in the asphalt mix slab with closest properties to in-service pavement due to $4 \%$ air voids, are suggested to be $8.0 \mathrm{kgf} / \mathrm{cm}^{2}$ and 75 respectively.

Upon completion of this study, one of the most important observations that can be made with regards to Turamesin is the compaction time. Turamesin seemed to be capable in fabricating slab within duration of 15 minutes for 75 numbers of passes, which can be considered as reasonable. The rolling speed of the roller compactor is about 10.5 rotations per minutes and one complete pass takes about 12 seconds. One slab compacted using Turamesin can produce up to 16 cylindrical core specimens of $100 \mathrm{~mm}$ diameter. When comparing the performance in terms of number of specimens produced over time, Turamesin seemed to be well ahead of the other types of compactor.

\section{CONCLUSIONS}

Based upon the test results and analysis, it was found that for a slab to be compacted to the desired ultimate compaction of $4 \%$ air voids, the applied pressure of $8.0 \mathrm{kgf} / \mathrm{cm}^{2}$ and 75 numbers of passes are required. The target air voids was selected based on researches and past performance that have shown that a final compacted void content of $4 \%$ is ideal for asphalt mixtures. Turamesin seemed to be capable in compacting slab within duration of 15 minutes for 75 numbers of passes, excluding mixing and coring. One slab is capable of producing 16 cylindrical core specimens of $100 \mathrm{~mm}$ diameter.

Currently, the optimum asphalt content for slab preparation was determined through Marshall mix design method, using Marshall Impact Compactor for specimen fabrication. As Marshall Impact Compactor was found to be least effective in terms field compaction simulation, Turamesin is therefore recommended to be use for specimen's preparation in determining the optimum asphalt content. In order to achieve the objective, it is recommended that the length of the mould of Turamesin be adjustable to cater for smaller dimension of slab. Also, future works should be conducted to evaluate the internal structure of the compacted slabs since degree and method of compaction are highly related to the internal structure. Digital image analysis and laser scanning are recommended to study the effect of compaction methods on internal structure of the slab specimens which is referred to the distribution of aggregates and air voids throughout the slab.

\section{ACKNOWLEDGEMENTS}

The authors would like to thank the Department of Civil Engineering of Universiti Putra Malaysia for providing facilities and support to this project and to all the people whom are directly and indirectly involved in the project for their help and cooperation in this study.

\section{REFERENCES}

1. Brown, E.R., 1990. Density of Asphalt ConcreteHow Much Is Needed? Research Report-NCAT Report No. 90-3, NCAT Auburn University

2. Button, J.W., D.W. Little, V. Jagadam and O.J. Pendleton, 1992. Correlation of Selected Laboratory Compaction Methods with Field Compaction. Texas Transportation Institute.

3. Consuerga, A., D.N. Little, H.V. Quintus and J. Burati, 1992. Comparative Evaluation of Laboratory Compaction Devices Based on Their Ability to Produce Mixtures with Engineering Properties Similar to Those Produced in The Field. Transportation Research Record, 1228: 80-87.

4. Harvey, J., 1992. Effects of Laboratory Specimen Preparation on Aggregate-Asphalt Structure, Air Void Content Measurement and Repetitive Simple Shear Test Results. Transportation Research Record, 1454: 113-122.

5. Khan, Z.A., H.I. Wahab, I. Asi and R. Ramadhan, 1998. Comparative Study of Asphalt Concrete Laboratory Compaction Methods to Simulate Field Compaction. Construction and Building Materials, 12: 373-384.

6. Khosla, N.P. and S. Sadasivam, 2002. Evaluation of the Effects of Mixture Properties and Compaction Methods on the Predicted Performance of Superpave Mixtures. Final Report FHWA/NC/2002-030, North Carolina State University.

7. Muniandy, R. and M.F. Zaharudin, 2004. Evaluation of Turamesin for SMA Slab Compaction. Thesis, Universiti Putra Malaysia, Malaysia.

8. Roberts, F.L., P.S. Kandhal, E.R. Brown, D.Y. Lee and T.W. Kennedy, 1996. Hot Mix Asphalt Materials, Mixture, Design and Construction (2nd Ed.). NAPA Education Foundation.

9. Sousa, J.B., J.A. Deacon and C.L. Monosmith, 1991. Effect of the Laboratory Compaction Methods on Permanent Deformation Characteristics of Asphalt Aggregate Mixtures. Proceedings Association of Asphalt Paving Technologist, 60: 533-585. 